\title{
The Chemical Structure of a Component of Citrullus colocynthis, SCHRAD.
}

\author{
By Kiroyasu Watanabe*, Akio Ine* and Yoshio Ogawa** \\ *Osaka Research Laboratory, Tanabe Seiyaku Co., Ltd., **National Inst. of Genetics, \\ Kihara Inst. for Biological Research
}

Received November 4, 1960

\begin{abstract}
A new substance, molecular formula $\mathrm{C}_{8} \mathrm{H}_{10} \mathrm{O}_{2}$, was isolated from the unripe fruits of Citrullus colocynthis, SCHRAD. Judging from the results of infrared absorption spectra, properties of the derivatives and the oxidative product of methyl derivative, this substance was pressumed to be p-hydroxybenzyl methyl ether and this assumption was proved beyond doubt by its direct comparison with an authentic synthesized sample.
\end{abstract}

Citrullus colocynthis, SCHARD is a kind of wild pernnial liana indigenous to Southeast Asia and Africa. The extract of its fruit is called colocynth, which has long been used as a purgative or a vermifuge.

In recent years Lavie et al.1) studied the chloroform extract of this fruit and made known that the extract had an anti-cancer property. The active substance is a glucoside, which yielded an aglucone $\mathrm{C}_{30} \mathrm{H}_{44} \mathrm{O}_{7}$ on hydrolysis. Recently2) the latter substance was found to be identical with the one obtained from Ecballium elaterium, A. RICH. On the other hand one of the present authors (Ogawa) and his collaborators made genetic and biochemical studies ${ }^{3,4)}$ on a bitter constituent of Citrullus colocynthis, SCHRAD., which they named "citbittol", and found that this substance is composed of eight components ${ }^{5}$ ) and has anti-cancer properties ${ }^{6}$ ).

1) D. Lavie, D. Willner, M. Belkin and W.G. Hardy, Abstract of synposium on the chemotherapy of cancer., (Tokyo, October. 1957).

2) D. Lavie and D. Willner, J. Am. Chem. Soc., 82, $1668(1960)$.

3) Y. Ogawa, and M. Shimotsuma, Ann. Rep. Nat. Inst. Gen., 9, 93 (1958).

4) M. Shimotsuma and Y. Ogawa, Jap. J. of Gin., 35, 15, 6), 143 (1960).

5) Y. Ogawa, and K. Furusato, Ann. Rep. Nat. Inst. Gen., 9, 92 (1958).

6) Y. Ogawa, Ann. Rep. Nat. Inst. Gen., 9, 94 (1958).
Lately the present authors have made a thorough chemical investigation of the components of Citrullus colocynthis, SCHRAD., and succeeded to isolate crystalline plates of m.p. $85 \sim 6^{\circ} \mathrm{C}$, beside a glucoside, which is probably the same as the one described by Lavie. The chemical structure of this crystalline substance, which was hitherto unknown in the literature, was now elucidated and the details are given below.

For isolation of this compound, unripe fruits, about 7 or 8 days after bearing, were collected and worked up as follows; Fig. 1.

From the molecular weight and analytical data, a molecular formula $\mathrm{C}_{8} \mathrm{H}_{10} \mathrm{O}_{2}$ was attributed to this substance.

As can be understood from the method of isolation given above, this substance is phenolic and moreover as such it gives positive test with ferric chloride and also with diazotized benzensulfanilic acid and sodium carbonate.

From the infrared data the presence of phenolic $\mathrm{OH}$ was also revealed (3.08, 7.40, $7.85 \mu)$ and the bands at $9.37 \mu, 12.03 \mu$ and $7.22 \mu$ may be associated with an ether linkage, a 1,4-disubstituted benzene ring and a methyl group respectively. The phenolic nature was 


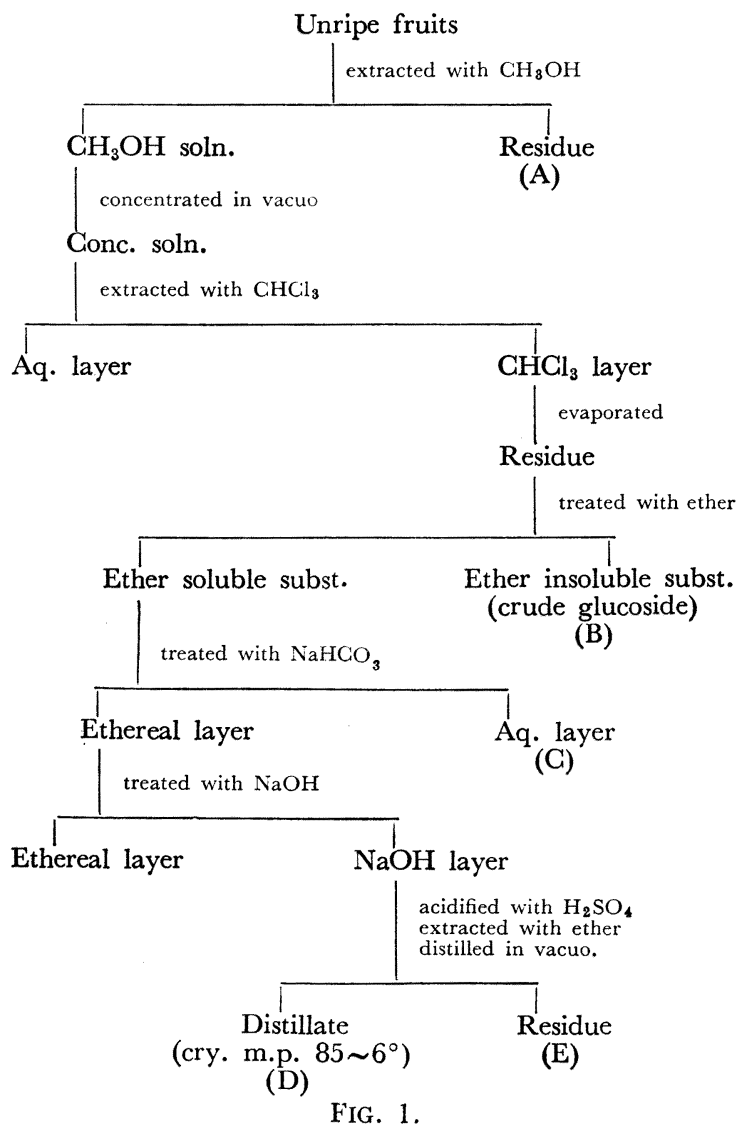

also supported from the fact that this substance gave mono $p$-toluenesulfonate and mono $p$-nitrobenzoate, both of which gave satisfactory analyses as such and are devoid of $\mathrm{OH}$ infrared absorption band.

The corresponding methyl ether, prepared with diazomethane, furnished $p$-methoxybenzoic acid by oxidation with potassium per- manganate.

Judging from the above mentioned data this substance was presumed to be $p$-hydroxybenzyl methyl ether and this assumption was proved by direct its comparison with an authentic specimen synthesized as follows; Fig. 2.

The ultimate compound thus prepared melted at $85 \sim 6^{\circ} \mathrm{C}$ alone or admixed with the natural product. Their infrared spectra also were identical.

\section{EXPRIMENTAL}

\section{Extraction and Isolation of (D)}

Thirteen liters of methanol were added to the $19.4 \mathrm{~kg}$ of crashed unripe fruits of Citrullus colocynthis, SCHRAD. After standing at room temperature for twenty four hrs. the mixture was filtered by press. The residue was again extracted with 131 of methanol and filtered. The combined filtrate was concentrated under reduced pressure to 41 and extracted with 41 of chloroform three times. The chloroform layer was concentrated to dryness under reduced pressure and treated with $200 \mathrm{ml}$ of ether to remove $10.1 \mathrm{~g}(0.052 \%$ of raw material) of insoluble substance. The insoluble substance was crude glucoside. The ethereal layer was extracted with dil. sodium bicarbonate solution to remove acids, and then extracted with 5 per cent sodium hydroxide solution to extracted phenolic substances. The alkaline layer was acidified with dil. sulfuric acid and extracted with ether. The extract was distilled under reduced pressure to yield $0.25 \mathrm{~g}$ $(0.0015 \%)$ of (D); b.p. $95 \sim 100^{\circ} \mathrm{C}$. The distilate, soon solidified, was recrystalized from benzene to give a colorless plate; m.p. 85 $86^{\circ}$ C. M.W. Found: 138. 141 . 139. (by K. Rast method) Calcd. for $\mathrm{C}_{8} \mathrm{H}_{10} \mathrm{O}_{2 .}$ : 138 . Anal. Found: C, 69.99; H, 7.25. Calcd. for $\mathrm{C}_{8} \mathrm{H}_{10} \mathrm{O}_{2}$; C, $69.54 ; \mathrm{H}, 7.31 \%$.

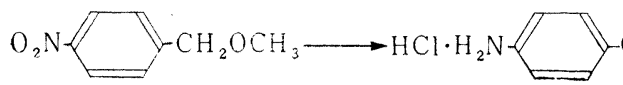

(I)
$\mathrm{CH}_{2} \mathrm{OCH}_{3}$<smiles>[1H]I</smiles>
$\mathrm{HO}^{-} \mathrm{N} \equiv \mathrm{N}^{+}$

(II)

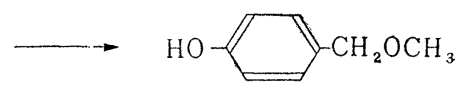

(III)

FIG. 2. 


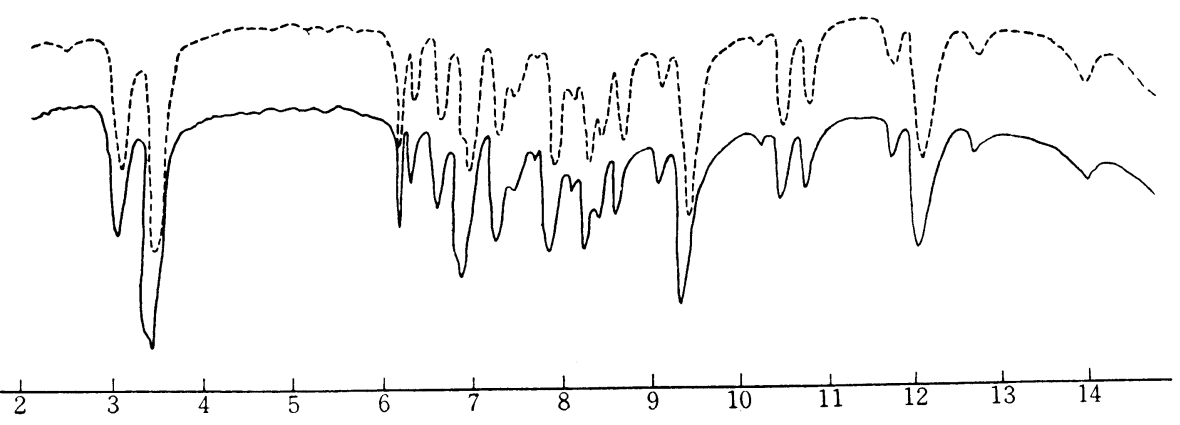

FIG. 3. Infrared Absorption Spectra of Natural and Synthesized p-Hydroxybenzyl Methyl Ether.

\section{p-Toluenesulfonate}

To a solution of $20 \mathrm{mg}$ of (D) in $0.2 \mathrm{ml}$ of absolute pyridine, $30 \mathrm{mg}$ of $p$-toluenesulfonylchloride in $0.2 \mathrm{ml}$ of absolute pyridine was added under cooling. After standing for twelve hrs. at room temperature $5 \mathrm{ml}$ of ice water was added. The separated oil immediately solidified. The crystal was filtered and recrystallized from 70 per cent ethanol to give a colorless needle; m.p. $45 \sim 46^{\circ}$ C. Anal. Found: C, 61.59; H, 5.52. Calcd. for $\mathrm{C}_{15} \mathrm{H}_{16} \mathrm{O}_{4} \mathrm{~S}$; C, 61.64; $\mathrm{H}, 5.52 \%$.

\section{p-Nitrobenzoate of (D)}

This experiment was carried out in the same procedure as above described. $p$-Nitrobenzoate was obtained as a slight yellow crystal: m.p. $92 \sim 93^{\circ} \mathrm{C}$. Anal. Found: C, 63.56; $\mathrm{H}, 4.22 ; \mathrm{N}, 4.86$. Calcd. for $\mathrm{C}_{15} \mathrm{H}_{13} \mathrm{O}_{5} \mathrm{~N}: \mathrm{C}$, $62.71 ; \mathrm{H}, 4.56 ; \mathrm{N}, 4.88 \%$.

\section{Oxidation of the Methyl Ether Derivative of (D)}

Eighty seven $\mathrm{mg}$ of (D) was added to an excess of ethereal diazomethane solution and allowed to stand for twenty four hrs. at room temperature. After evaporating the solvent and the excess of diazomethane, the residue was dissolved in $10 \mathrm{ml}$ of ether, shaken with 2 per cent sodium hydroxide solution to remove the original substance, washed with water, dried, evaporated and distilled under reduced pressure to yield $58 \mathrm{mg}$ of colorless liquid: b.p. $90 \sim 95^{\circ} \mathrm{C}$ (oil bath temperature). Fourty $\mathrm{mg}$ of the methyl ether derivative in $4 \mathrm{ml}$ of 50 per cent aqueous pyridine was oxidized to carboxylic acid with $160 \mathrm{mg}$ of potassium permanganate in $10 \mathrm{ml}$ of water dropping in a period of twenty minutes. The solution was heated on water bath until the color of permanganate disappeared. After the oxidation of the methyl ether derivative was completed, the separated manganese dioxide was filtered by suction and washed with acetone. The combined filtrate was concentrated under reduced pres-

\section{......- Synthesized}

sure to $3 \mathrm{ml}$ and acidified with hydrochloric acid to congored reaction. The separated crystals were filtered and recrystallized from ethanol to give a needle crystal: m.p. $184^{\circ} \mathrm{C}$. The mixed melting point with the authentic $p$-methoxybenzoic acid was not depressed.

\section{Synthesis of $p$-Hydroxylbenzyl Methyl Ether.}

Two point seven gr of $p$-aminobenzyl methyl ether were dissolved in $7.4 \mathrm{~g}$ of 10 per cent hydrochloric acid and diluted to $100 \mathrm{ml}$ with water. To this solution, $3.5 \mathrm{~g}$ of sodium nitrite in $15 \mathrm{ml}$ of water was added at room temperature. The mixture was stirred for one hr. at room temperature, for thirty minutes at $70^{\circ} \mathrm{C}$, and finally for thirty minutes at $90 \sim 95^{\circ} \mathrm{C}$. After cooling the separated oily substance was extracted with cther and the ethereal layer was extracted with 5 per cent sodium hydroxide solution. The alkaline solution was acidified with hydrochloric acid and extracted with ether. The ethereal layer was dried, evaporated and distilled under reduced pressure to yield $0.4 \mathrm{~g}$ : b.p. $195 \sim 100^{\circ} \mathrm{C}$. The distilate, soon solidified, was recrystallized from benzene to give a colorless plate: m.p. $85 \sim 86^{\circ} \mathrm{C}$. The mixed melting point with the natural substance was not depressed. Anal. Found: $\mathrm{C}, 69.68 ; \mathrm{H}, 6.95$. Calcd. for $\mathrm{C}_{8} \mathrm{H}_{10} \mathrm{O}_{2}: \mathrm{C}$, $69.54 ; \mathrm{H}, 7.30 \%$.

Acknowledgement The authors express their gratitudes to Dr. M. Fujisawa and Dr. N. Sugimoto of Research Laboratory, Tanabe Seiyaku Co. Ltd. for their guidances and encouragements. They are also indebted to Mr. K. Kodera for infrared spectral data and to the members of Analytical Laboratory of Tokyo Research Laboratory, Tanabe Seiyaku Co. Ltd. 